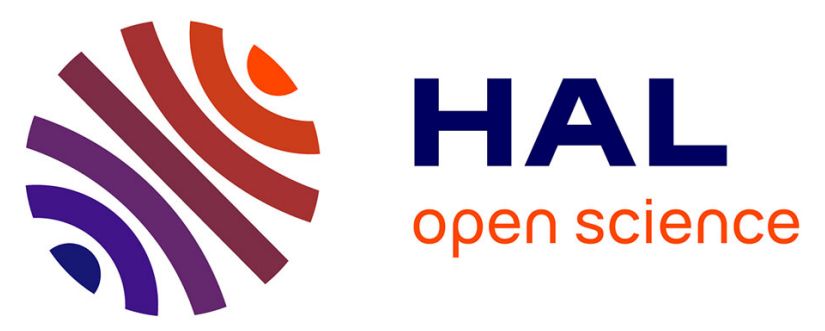

\title{
Antischistosomal efficacy of artesunate combination therapies administered as curative treatments for malaria attacks
}

\author{
Denis Boulanger, Yemou Dieng, Badara Cissé, Franck Remoue, Frédéric \\ Capuano, Jean-Louis Dieme, Tofène Ndiaye, Cheikh Sokhna, Jean-François \\ Trape, Brian Greenwood, et al.
}

\section{To cite this version:}

Denis Boulanger, Yemou Dieng, Badara Cissé, Franck Remoue, Frédéric Capuano, et al.. Antischistosomal efficacy of artesunate combination therapies administered as curative treatments for malaria attacks. Transactions of The Royal Society of Tropical Medicine and Hygiene, 2007, 101 (2), pp.113116. $10.1016 / j . t r s t m h .2006 .03 .003$. ird-00177064

\section{HAL Id: ird-00177064 https://hal.ird.fr/ird-00177064}

Submitted on 5 Oct 2007

HAL is a multi-disciplinary open access archive for the deposit and dissemination of scientific research documents, whether they are published or not. The documents may come from teaching and research institutions in France or abroad, or from public or private research centers.
L'archive ouverte pluridisciplinaire HAL, est destinée au dépôt et à la diffusion de documents scientifiques de niveau recherche, publiés ou non, émanant des établissements d'enseignement et de recherche français ou étrangers, des laboratoires publics ou privés. 
Running head : dual efficiency of artesunate against Plasmodium and Schistosoma

Title : Anti-schistosome efficacy of artesunate combination therapies when administered as curative treatments of malaria attacks

Authors : Denis BOULANGER ${ }^{\mathrm{a},{ }^{*}}$, Yemou DIENG ${ }^{\mathrm{b}}$, Badara CISSE $^{\mathrm{b}, \mathrm{c}, \mathrm{d}}$, Franck REMOUE ${ }^{\mathrm{a}}$, Frederic CAPUANO ${ }^{\mathrm{a}}$, Jean-Louis DIEME, Tofene NDIAYE ${ }^{\mathrm{a}}$, Cheikh SOKHNA ${ }^{\mathrm{c}}$, Jean-François TRAPE ${ }^{\mathrm{c}}$, Brian GREENWOOD ${ }^{\mathrm{d}} \&$ Francois SIMONDON ${ }^{\mathrm{a}}$

${ }^{a}$ Institut de Recherche pour le Développement, UR024, Dakar, Senegal and Montpellier, France.

${ }^{b}$ University Cheikh Anta Diop, Dakar, Senegal.

'IRD, UR077, Dakar, Senegal.

${ }^{\mathrm{d}}$ London School of Hygiene \& Tropical Medicine, London, UnitedKingdom.

* : corresponding author. E-mail : Denis.Boulanger@ird.sn. IRD, Campus de Hann, UR024, BP 1386, CP 18524, Dakar, Senegal. Tel. +221 84935 33. Fax. +2218324307 . 


\begin{abstract}
Artesunate is a highly effective anti-malarial and there is some evidence that it is also active against schistosome infections. Therefore, we investigated whether treatment with artesunate of acute malaria in Senegalese children had an impact on their level of infection with Schistosoma haematobium. Twenty seven children entered into a clinical trial of antimalaria treatment were excreting eggs of $S$. haematobium in their urine on the day of treatment, 15 of whom received the combination of a single dose of sulfadoxine/pyrimethamine together with three daily doses of artesunate $(4 \mathrm{mg} / \mathrm{kg})$, the remaining 12 children receiving three daily doses of amodiaquine and artesunate. The overall cure rate and reduction in the mean number of excreted eggs 28 days post-treatment were $92.6 \%$ and $94.5 \%$, respectively. Our findings indicate that artesunate, in addition to being a very effective treatment for uncomplicated malaria, can also reduce sharply the $S$. haematobium loads harboured by pre-school African children.
\end{abstract}

Key-words : artesunate, Schistosoma haematobium, malaria, chemotherapy, Senegal. 


\section{Introduction}

Provision of an effective anti-malarial for the treatment of uncomplicated malaria is the corner stone of antimalarial control programmes in Africa (WHO, 2000). Because of progressive loss of efficacy of previously widely used antimalarials such as chloroquine and sulphadoxine/pyrimethamine, most African national malaria control programmes and the World Health Organisation now recommend artemisinin-based combination therapies (ACTs) as the first line of treatment for uncomplicated malaria in Africa (Olliaro et al., 2001). Numerous clinical trials have demonstrated their safety and efficacy. Surprisingly, both artesunate and artemether have also proved to have activity against several species of schistosomes (Xiao, 2005). There is, however, debate about their use on a large scale to control the second most prevalent parasitic disease worldwide. Because of the overlapping distributions of schistosomiasis and malaria, the risk that widespread use of artemisinins for the treatment of schistosomiasis could favour the emergence of resistant strains of Plasmodium must be seriously considered (Menard et al., 2005; Utzinger et al., 2001). Nevertheless, there is a possibility that use of artemisinins to treat malaria could have, as a secondary effect, a beneficial effect on the burden of schistosomiasis (Utzinger et al., 2003) but there is no information so far on how effective artemisinins might be against schistosome infections when used in this way. Like in many other African countries, chloroquinoresistance has reached in Senegal such a level (Trape et al., 1998) that the National 
Program had to consider a change of malaria case management. Therefore, we have taken advantage of a clinical trial of two different forms of ACTs conducted in a rural area to evaluate if artesunate, when used for the treatment of uncomplicated malaria, also has an impact on the schistosome burden of young Senegalese children.

\section{Materials and Methods}

\section{Study area and population}

The study took place between November 2003 and January 2004, at the end of the rainy season, in four villages located within the community of Niakhar site, situated $145 \mathrm{kms}$ east from Dakar, where regular demographic surveillance has been maintained since 1963 (Delaunay et al., 2001). These villages are situated in an area where water collections, either temporary (marshy lands) or semi-permanent (ponds used for agricultural purposes), are potential sites for the breeding of Anopheles mosquito larvae and of Bulinus snails, resulting in a high level of both Plasmodium falciparum malaria and of urinary schistosomosis in the community (Briand et al., 2005). 518 children, aged between 15 and 74 months old at the start of the study, were eligible.

\section{Detection of malaria}

Malaria cases were detected through both passive surveillance at health centres and weekly domiciliary visits. Malaria was defined as an illness associated with an auricular temperature of $37.5^{\circ} \mathrm{C}$ or greater and/or a 
history of fever or vomiting during the previous 24 hours, accompanied by the detection of asexual malaria parasites on blood film examination. Blood smears were performed 3, 7, 14 and 28 days post-treatment to detect any persistence of parasites after treatment.

\section{Chemotherapy}

Children with malaria were randomised to receive treatment with artesunate (AS, Sanofi, Paris, France) given either with sulfadoxine/pyrimethamine (SP) or amodiaquine (AQ), both provided by the Senegalese National Pharmaceuticals Company. SP $(25 \mathrm{mg} / \mathrm{kg}$ sulfadoxine $+1.25 \mathrm{mg} / \mathrm{kg}$ pyrimethamine) was administered once on the first day of treatment. Amodiaquine was used at a dose of $10 \mathrm{mg} / \mathrm{kg}$ for the first 2 days, then $5 \mathrm{mg} / \mathrm{kg}$ on the third day. Artesunate $(4 \mathrm{mg} / \mathrm{kg})$ was given once daily for three consecutive days. All treatments were given under direct observation.

\section{Detection of schistosome infection}

As soon as a malaria case was microscopically confirmed, a field worker visited the child, started chemotherapy and left a container with the child's mother together with instruction to collect the urine from a whole micturition the following morning (Day 0). In the laboratory, the volume of the sample was recorded (range : $3-325 \mathrm{ml}$ ), the urine was filtered through a nylon disc filter $\left(\right.$ Nytrel $\left.{ }^{\circledR}\right)$ with a $30 \square$ mesh and the numbers of eggs trapped on the filter counted under a dissecting microscope. The same procedure was repeated on Days 1,2,28, 29 and 30 after the start of 
antimalarial treatment, before any re-infection larva could have become an adult fertile schistosome.

\section{Data processing}

Data were independently recorded by two data entry clerks and then checked for concordance. Aberrant values were identified and corrected. Levels of egg excretion were expressed as the number of eggs per $10 \mathrm{ml}$ of urine. Malaria cases were considered as eligible for inclusion in the study if the results of at least two filtrations before and after treatment were available. At least one of the pretreatment samples had to be positive before a case was included in the efficacy analysis. Cure rate was expressed as the percentage of children who became completely negative after treatment. Geometric means minus 1 of the available daily counts plus 1 were used to calculate the mean levels of individual egg excretions before (mean of Days 0-1-2) and after (mean of Days 28-29-30) treatment. Group mean egg excretion was calculated as the geometric mean minus 1 of the individual mean counts plus 1 .

\section{Statistical analysis}

Yates' corrected chi-2 was used to compare cure rates. Exact 95\% confidence intervals (CI) were calculated for proportions. Mann-Whitney U test and Wilcoxon signed-rank test were run to assess the significance of the differences between means of unpaired and paired values, respectively.

\section{Ethical clearance}

Informed consent was obtained from the children's mothers and the global 
protocol received approval from the Senegalese National Ethics

Committee. All children who were still excreting schistosome eggs on either Day 28-29-30 were treated with praziquantel (BILTRICID ${ }^{\circledR}$ ) at a 40 $\mathrm{mg} / \mathrm{kg}$ dosage.

\section{Results}

108 cases of malaria meeting the study definition were detected among 518 children during the period of the survey. Twenty-seven of these children also met the study criterion for a diagnosis of urinary schistosomiasis, 12 and 15 in the $\mathrm{AQ} 3+\mathrm{AS} 3$ and $\mathrm{SP} 1+\mathrm{AS} 3$ groups respectively. Fifteen were male and their age varied from 26 to 74 months. All of them were successfully cured of Plasmodium infection, as shown by negative 3, 7, 14 and 28 day blood smears. The mean level of egg excretion before treatment was higher in the SP1+AS3 group than in the AQ3 +AS3 group (Table) but the difference between the groups was not significant $(p=0.097)$. Twentyfive children were totally negative for schistosome eggs after treatment, an overall cure rate of $92.6 \%$. Cure rates did not differ significantly between the two groups $(p=0.84)$. All children in the AQ3+AS3 were cured $(p<$ 0.005). In the SP1+AS3 group, the mean number of eggs was reduced by more than $90 \%$ (pre- versus post-treatment means comparison, $\mathrm{p}<0.001$ ).

\section{Discussion}

The main goal of this study was to determine if artesunate, when 
administered for the treatment of young children against malaria, also had an effect on Schistosoma haematobium egg output. So far, three randomised clinical trials have investigated the capacity of artesunate to cure established $S$. haematobium infections but with divergent results. The first one, done in Gabon using a dosage of $4 \mathrm{mg} / \mathrm{kg} / \mathrm{day}$ of artesunate, once a day over three days (Borrmann et al., 2001), concluded that it was not effective at all. In contrast, 8 tablets of $50 \mathrm{mg}$ over 5 days delivered in Senegal (De Clercq et al., 2002) or two doses of $6 \mathrm{mg} / \mathrm{kg}$ administered two weeks apart in Nigeria (Inyang-Etoh et al., 2004) provided good evidence of efficacy with mean reductions of egg excretion ranging from 55 to $89 \%$, 5 to 6 weeks after treatment. However, these three studies involved schoolchildren between 5 and 18 years who were harbouring heavy infections. Our study is the first undertaken in children less than 6 years old who had malaria at the time that they were treated. Both artesunatecontaining combination therapies led to marked reductions in egg counts, above $90 \%$. The association of artesunate and amodiaquine completely cured all children who received this combination which ranks number two behind artemether/lumefantrine in WHO recommendations as first line of treatment of uncomplicated malaria (Majori, 2004). The combination of SP with artesunate was slightly less effective but numbers were small. It is unlikely that the partners of artesunate contributed to the activity seen against schistosome infections and one can reasonably assume that artesunate was the active drug. 
This pilot study has a number of weaknesses. Firstly, there was no control group and some of the negative counts obtained at the end of the trial could have resulted from natural fluctuations in egg excretion. However, these could not explain the very high levels of 28 day cure obtained and repeated filtrations of a whole micturition are a way to prevent false negatives. Secondly, the study was conducted in an area of relatively low schistosome endemicity with an overall mean egg count of $0.5 \mathrm{eggs} / 10 \mathrm{ml}$ of urine. It cannot be speculated that such satisfactory results would be obtained in children with much higher levels of infection but, in Sahelian countries, malaria strikes mainly during the first five years of age at a time when heavy schistosome loads are unfrequent. Finally, the number of children in the study was small, making comparisons between groups able to detect only major differences. Despite these reservations, our findings suggest that adoption of artemisinin-based combination therapies as first lines of treatment for malaria in many African countries, including Senegal, may have an added benefit by reducing the burden of schistosomiais in the many areas where both infections are found. Moreover, such bitherapies are also strongly supported as a basis for intermittent preventive treatment, especially in children less than 5 years (Cisse et al., 2006). It would be of great value to assess if, within the framework of a global strategy, both curative and preventive, against malaria, artesunate could also reduce schistosomiasis impact. However, our study was only a pilot trial involving children under the age of five years participating in a malaria study. There 
is a need to confirm our findings in other areas where ACTs are used as first line treatment for malaria. In addition, there is a need for studies in older children, in whom schistosome burdens are likely to be heavier than was the case in this study, and for trials in areas where $S$. mansoni is the dominant species.

\section{Conflicts of interest statement}

The authors declare to have no known conflict of interest. The sponsors and the artesunate provider (Sanofi) did not interact in the management of the study nor in the data analysis.

\section{Acknowledgments}

We would like to specially thank the population of the Niakhar site for its willingness to participate to the study and the IRD Service Unit 009 for maintenance of the Niakhar database. Skillful participation of Ernest Faye, Ibou Cissé and Agnès Bakhoum is greatly acknowledged. This work was funded by the French Ministry of Research and Technology (PAL+ contract \#2829), by the University Cheikh Anta Diop of Dakar, by the Bill and Melinda Gates Foundation and by the Institut de Recherche pour le Développement. Sanofi donated artesunate tablets. 


\section{BIBLIOGRAPHY}

Borrmann, S., Szlezak, N., Faucher, J.F., Matsiegui, P.B., Neubauer, R., Binder, R.K., Lell, B. \& Kremsner, P.G., 2001. Artesunate and praziquantel for the treatment of Schistosoma haematobium infections: a double-blind, randomized, placebo-controlled study. J. Infect. Dis., 184, 1363-1366.

Briand, V., Watier, L., Le Hesran JY, Garcia, A. \& Cot, M., 2005.

Coinfection with Plasmodium falciparum and Schistosoma haematobium: protective effect of schistosomiasis on malaria in senegalese children? Am. J. Trop. Med. Hyg., 72, 702-707.

Cisse, B., Sokhna, C., Boulanger, D., Milet, J., Ba, E., Richardson, K., Hallett, R., Sutherland, C., Simondon, K., Simondon, F., Alexander, N., Gaye, O., Targett, G., Lines, J., Greenwood, B. \& Trape, J.-F., 2006. Seasonal intermittent treatment with artesunate and sulfadoxinepyrimethamine for prevention of malaria in Senegalese children: a randomised, placebo-controlled, double-blind trial. Lancet, 367, 659-67. De Clercq, D., Vercruysse, J., Kongs, A., Verle, P., Dompnier, J.P. \& Faye, P.C., 2002. Efficacy of artesunate and praziquantel in Schistosoma haematobium infected schoolchildren. Acta Trop., 82, 61-66.

Delaunay, V., Etard, J.F., Preziosi, M.P., Marra, A. \& Simondon, F., 2001. Decline of infant and child mortality rates in rural Senegal over a 37-year period (1963-1999). Int. J. Epidemiol., 30, 1286-1293. 
Inyang-Etoh, P.C., Ejezie, G.C., Useh, M.F. \& Inyang-Etoh, E.C., 2004. Efficacy of artesunate in the treatment of urinary schistosomiasis, in an endemic community in Nigeria. Ann. Trop. Med. Parasitol., 98, 491-499. Majori, G., 2004. [Combined antimalarial therapy using artemisinin]. Parassitologia, 46, 85-7.

Menard, D., Matsika-Claquin, M.D., Djalle, D., Yapou, F., Manirakiza, A., Dolmazon, V., Sarda, J. \& Talarmin, A., 2005. Association of failures of seven-day courses of artesunate in a non-immune population in Bangui, Central African Republic with decreased sensitivity of Plasmodium falciparum. Am. J. Trop. Med. Hyg., 73, 616-621.

Olliaro, P., Taylor, W.R. \& Rigal, J., 2001. Controlling malaria: challenges and solutions. Trop. Med. Int. Health, 6, 922-927.

Trape, J.F., Pison, G., Preziosi, M.P., Enel, C., Desgrees du Lou, A., Delaunay, V., Samb, B., Lagarde, E., Molez, J.F. \& Simondon, F., 1998. Impact of chloroquine resistance on malaria mortality. C. R. Acad. Sci. III, 321, 689-697.

Utzinger, J., Keiser, J., Shuhua, X., Tanner, M. \& Singer, B.H., 2003.

Combination chemotherapy of schistosomiasis in laboratory studies and clinical trials. Antimicrob Agents Chemother, 47, 1487-95.

Utzinger, J., Xiao, S., Keiser, J., Chen, M., Zheng, J. \& Tanner, M., 2001. Current progress in the development and use of artemether for chemoprophylaxis of major human schistosome parasites. Curr Med Chem, $8,1841-60$. 
WHO, 2000. WHO Expert Committee on Malaria. World Health Organ.

Tech. Rep. Ser., 892, i-v, 1-74.

Xiao, S.H., 2005. Development of antischistosomal drugs in China, with particular consideration to praziquantel and the artemisinins. Acta Trop., $96,153-167$. 
Table. Cure rates and mean egg excretions in children undergoing two distinct artesunate combination therapies.

\begin{tabular}{|c|c|c|c|c|}
\hline & Group & $\mathrm{AQ} 3+\mathrm{AS} 3$ & $\mathrm{SP} 1+\mathrm{AS} 3$ & Both AS3 \\
\hline \multirow[t]{4}{*}{ Cure rates } & $\mathrm{n}^{\circ}$ of included children & 12 & 15 & 27 \\
\hline & $\mathrm{n}^{\circ}$ of cured children & 12 & 13 & 25 \\
\hline & $\%$ cure rate & $100 \%$ & $86.7 \%$ & $92.6 \%$ \\
\hline & $95 \% \mathrm{CI}$ & $73.5-100.0 \%{ }^{\mathrm{a}}$ & $59.5-98.3 \%$ & $75.7-99.1 \%$ \\
\hline \multirow[t]{3}{*}{ Mean egg counts ${ }^{b}$} & before treatment & 0.233 & 0.403 & 0.325 \\
\hline & after treatment & 0.000 & 0.033 & 0.018 \\
\hline & $\%$ reduction & $100 \%$ & $91.9 \%$ & $94.5 \%$ \\
\hline
\end{tabular}
${ }^{\mathrm{a}}: 97.5 \% \mathrm{CI}$ (one-sided)
${ }^{b}$ : geometric means 